\title{
Traditional Practices in Infant Care a Province in Eastern Region of Turkey
}

\author{
Ayten Yilmaz Yavuz ${ }^{1}$, Yeşim Aksoy Derya ${ }^{2}$, Hacer Gök Uğur ${ }^{3}$ \\ ${ }^{1}$ Department of Public Health Nursing School of Health, Recep Tayyip Erdoğan University, Rize, Turkey \\ ${ }^{2}$ Department of Midwifery, Faculty of Health Sciences, Inönü University, Malatya, Turkey \\ ${ }^{3}$ Department of Public Health Nursing, Faculty of Health Sciences, Ordu University, Ordu, Turkey
}

Received: 03 May 2020, Accepted: 29 August 2020, Published online: 31 August 2020

(C) Ordu University Institute of Health Sciences, Turkey, 2020

\begin{abstract}
Objective: This study was conducted to find out the traditional methods applied in infant care in Turkish culture.

Methods: This study is a descriptive study in a city in the east of Turkey between February and August 2017. Women who participated in the study were chosen with improbable random sampling method. The data were collected with questionnaire form by using face-to- face interview method. Descriptive statistics were used in data analysis

Results: The most common postnatal practices were reciting the azan to the infant's ear $(66.2 \%)$ and swaddling (44.4\%). In addition, it was found that before the first feeding of the infant, azan was recited $(16.2 \%)$ and honey was placed on the infant's mouth (21.4\%). The most common practice for the health care of the infant was to cover with a yellow cloth/muslin/blanket to prevent jaundice (47.6\%), while the most common spiritual care practices were evil eye bead (37.1\%) and to put a Koran on the cradle to prevent the infant from getting sick in the first 40 days $(33.6 \%)$.

Conclusion: It was found that the puerperal women conducted traditional practices such as for umbilical stump to fall off, to prevent jaundice, to recover from jaundice, for moniliasis, for diaper rash, for cough, for diarrhea, for constipation, for fever, for gas for infants who cry and who are uneasy all the time, before the first feeding religious ritual in the infants care.
\end{abstract}

Key words: Home care, Infant, Traditional

Suggested Citation: Yilmaz Yavuz A, Aksoy Derya Y, Gok Ugur H. Traditional Practices in Infant Care a Province in Eastern Region of Turkey. Middle Black Sea Journal of Health Science, 2020; 6(2):257-266.

\section{Address for correspondence/reprints:}

Ayten Yilmaz Yavuz

Telephone number: +90 (464) $2141059 / 3913$

ORCID-ID 0000-0002-5861-4254

E-mail: ayten.yilmaz@erdogan.edu.tr

DOI: $10.19127 / \mathrm{mbsjohs.731235}$

Note: This study was presented as a poster presentation at the National and International participation Congress of Home Health and Care, 23-25 November 2017, Istanbul/Turkey

\section{Introduction}

In addition to having significance in terms of monitoring and assessing health programs and determining future policies, neonatal, postneonatal infant and child deaths are also indicators of the society's development levels (Toruner ve Buyukgonenc, 2012). While infant death rate has been reported as 31.7 per thousand globally, as 9.8 per thousand in WHO Europe and as 5.8 per thousand in high-income group families, it is reported to reach 7.3 per thousand in 2016 from 52.6 per thousand in 1993 (Mollahaliloglu et al., 2011; Health Staistics Yearbook, 2016). It can be seen that the decrease in the last 23 years still did 
not reach the level of developed country. The fact that prenatal and natal reasons rank first are among reasons for infant and child deaths shows that problems about newborn and mother are still on the forefront in our country. There are various postnatal beliefs and practices in the world and in our country such as cutting the umbilical cord, placental practices, breastfeeding, practices for the umbilical stump's falling off and practices after the stump falls off, naming the baby, incubus, practices on the 40th day of the baby, bathing, baby's talking a lot and beautifully, choice of profession, evil eye, jaundice, fever, moniliasis, diaper rash, rash, cough, diarrhea, phlegm and tapeworm. Economic reasons, lack of information and service about maternal and infant health are determinants in preferring such traditional practices (Bozkaya et al., 2008; Kesterton and Cleland, 2009; Boer and Lamxay, 2009; Bulbul et al., 2009; Gokduman and Balkaya, 2010; Titaley et al., 2010; Amin et al., 2010).

Since infants' immune, central nervous and gastrointestinal systems are not completely developed, alternative methods are more important. For this reason, it is important to determine which of these practices are useful and which are harmful to prevent harmful ones from being used by the society and to encourage useful ones for being used. In addition, health professionals should inform mothers on the subject, support mothers for making the right choice and make sure that mothers are aware of the consequences and side effects of traditional practices (Sevig and Tanriverdi, 2014).

The purpose of this study is to find out the traditional infant care practices in puerperas in the puerperal service of the Training and Research Hospital in a city in the east of Turkey.

\section{Methods}

\section{Study Design and Setting}

This study, which was designed as a descriptive study to find out traditional practices in infant care, was conducted in the puerperal service of the Training and Research Hospital in a city in the east of Turkey. The universe of the study consists of puerperas who gave birth in the aforementioned hospital between February and August 2017. The number of women who gave birth in the aforementioned hospital between January 2016 and December 2016 is 4425. In the calculation of sample size, OpenEpi, version 3 general use statistical software was used (http://www.openepi.com) sample size was determined as at least 426 puerperas with a 0.05 level of significance, $97 \%$ confidence interval and $80 \%$ ability of representing the universe. Until the determined sample size was reached, women who gave birth in the aforementioned hospital and who met the inclusion criteria were chosen through improbable random sampling method. The inclusion criteria were participants' being literate, not having any psychiatric diagnosis and absence of postnatal complications in the mother and the infant. In the collection of data, the most suitable time for the mother and the infant was taken into consideration and the data were collected by the researchers through face to face interview method.

\section{Ethical issues}

Before starting the study, written permission from the institution the research was conducted in and approval from University Non-Invasive Clinical Researches Ethical Board (decision number: 08/06.01.2017) were taken. In addition, the participants were informed about the research and told that their individual information would be protected and volunteers were included in the study.

\section{Instruments}

For data collection, "Introductory Information Form" which was prepared to find out the sociodemographic characteristics of the puerperas (age, level of education, state of working, level of income, etc) and "Traditional Practices Information Form" which was prepared in line with the literature (Celasin et al., 2008; Vurur et al., 2009; Kesterton and Cleland, 2009; Gokduman and Balkaya, 2010) to find out the traditional practices used in infant care were used. Traditional Practices Information Form includes questions about traditional practices conducted in the hospital or at home after the baby is born (first feeding/breastfeeding of the baby, bathing the baby, belly button care, swaddling, jaundice, diaper rash, rash, fever, gas problems and spiritual care (baby's not being scared, not getting ill in the first forty days).

\section{Data analysis}

The data were assessed with SPSS 16.0 for Windows software (SPSS Inc., Chicago, IL, USA). In the study, descriptive statistics (numbers, percentages, averages, Standard deviation) were used to find out the traditional methods used in 
infant care and the participants' introductory characteristics.

\section{Results}

When the distribution of participants' sociodemographic characteristics was examined, it was found that their average age was $27.08 \pm 5.66$, $44.1 \%$ were high school graduates, $39.9 \%$ did not have a job and $72.8 \%$ had nuclear family. $66.9 \%$ of the participants stated that they lived in city center and $88.5 \%$ stated that they had social security. $63.6 \%$ of the participants stated that their income was equal to their expenditure. $94.8 \%$ of the participants stated that their spouses had a job and $41.8 \%$ stated that their spouses' level of education was high school (Table 1).

Table 1. Distribution of participants' sociodemographic characteristics $(n=426)$

\begin{tabular}{|c|c|c|}
\hline \multirow{2}{*}{$\begin{array}{l}\text { Variable } \\
\text { Age } \\
\end{array}$} & \multicolumn{2}{|c|}{ Mean \pm SD } \\
\hline & \multicolumn{2}{|c|}{$27.08 \pm 5.66$} \\
\hline Level of Education & n & $\%$ \\
\hline Literate/Primary & 62 & 14.6 \\
\hline Secondary & 57 & 13.4 \\
\hline High school & 188 & 44.1 \\
\hline University & 119 & 27.9 \\
\hline \multicolumn{3}{|l|}{ State of being employed } \\
\hline Yes & 170 & 39.9 \\
\hline No & 256 & 60.1 \\
\hline \multicolumn{3}{|l|}{ Spouse's level of education } \\
\hline Literate/Primary & 45 & 10.6 \\
\hline Secondary & 45 & 10.6 \\
\hline High school & 178 & 41.8 \\
\hline University & 158 & 37.0 \\
\hline \multicolumn{3}{|l|}{$\begin{array}{l}\text { Spouse's state of being } \\
\text { employed }\end{array}$} \\
\hline Yes & 404 & 94.8 \\
\hline No & 22 & 5.2 \\
\hline \multicolumn{3}{|l|}{ Family structure } \\
\hline Nuclear & 310 & 72.8 \\
\hline Traditional & 116 & 27.2 \\
\hline \multicolumn{3}{|l|}{ State of income } \\
\hline Less than expenditure & 78 & 18.3 \\
\hline Equal to expenditure & 271 & 63.6 \\
\hline More than expenditure & 77 & 18.1 \\
\hline \multicolumn{3}{|l|}{ Place of residence } \\
\hline City & 285 & 66.9 \\
\hline Town & 90 & 21.1 \\
\hline Village & 51 & 12.0 \\
\hline \multicolumn{3}{|l|}{ Social Security } \\
\hline Yes & 377 & 88.5 \\
\hline No & 49 & 11.5 \\
\hline Total & 426 & 100.0 \\
\hline
\end{tabular}

Table 2 shows the traditional practices used by the participants in terms of the newborn's health care. It was found that the first place participants referred to when the infant got sick was health institutions with a rate of $73.7 \%$. It was found that $19.5 \%$ of the participants did not bathe the infant for the stump to fall off, $47.7 \%$ covered with a yellow cloth/muslin/blanket to prevent jaundice, $41.1 \%$ took the infant to doctor for jaundice. The most used two practices were "taking to doctor/getting medicine (32.3\%)", "cleaning with carbonated water, throwing cotton cleaned with carbonated water on the ceiling and believing that the infant gets well when it falls down, making the infant drink water, cleaning with starch, cleaning the mouth with water from the container dogs drink water, putting on ring (24.6\%)" for moniliasis, "taking to doctor/applying cream (33.0\%)", "using powder (14.6\%)" for diaper rash, " taking to doctor/using medicine (38.2\%)", "using herbal products $(26.7 \%) "$ for cough, " taking to doctor/using medicine $(41.3 \%)$ ", "making the infant drink water frequently, breastfeeding often, making the infant eat banana (24.9\%) for diarrhea, " taking to doctor/using medicine (27.6\%)", "massaging the abdomen, making the infant drink olive oil, making the infant drink water frequently, making the infant eat fruit puree, soap from the anus as suppository, making the infant drink compost, making the infant drink fish oil (37.9\%)" for constipation, "applying cold compress (37.1\%)", " taking to doctor/using medicine (19.9\%)" for fever and "massaging, rubbing the back, making the infant drink herbal tea/tea, putting on apple oil $(61.4 \%)$ "for gas, praying for the infant that got uneasy $(15.0 \%)$ and waiting for reciting of azan, making the infant drink zam-zam applying date on the infant's mouth and making the infant drink blessed water as a religious ritual (14.1\%), before the first feeding .

When the cultural beliefs used by the participants in term o the newborn's were examined, it was found that $37.1 \%$ put evil eye bead on the infant to protect the infant from evil eye. Other cultural practices are "reading prayer, putting on amulet, pouring lead for evil eye, putting sour apple in swaddle (32.6\%). In addition, it was found that $30.8 \%$ put mother's milk on the infant face so that the infant would be beautiful, swaddled the infant $(44.4 \%)$ for the infant's body to be smooth, $27 \%$ put salt in the bathing water of the infant so that the infant would not smell, $33.6 \%$ put Quran on the cradle to prevent the baby from getting ill in the first 40 days, $31.9 \%$ talked to the infant so that the infant would be talkative, putting honey in the infant's mouth before the first feeding $(21.4 \%)$ for infants to be sweet talker. 


\section{Traditional Practices in Infant Care}

Table 2. Distribution of traditional practices conducted on health care of the newborn by the participants

\begin{tabular}{lcc}
\hline *Variable & n & \% \\
\hline The persons to contact first when the infant gets sick & 112 & 26.3 \\
\hline Family elders & 314 & 73.7 \\
$\quad$ Health institutions & 268 & 62.9 \\
\hline For umbilical stump to fall off & 83 & 19.5 \\
\hline No practices & 75 & 17.6
\end{tabular}

Cleaning with alcohol, putting on powder, putting on batticon, bathing the infant with salted water, putting cinder on the stump

To prevent jaundice

$\begin{array}{lcc}\text { No practices } & 128 & 30.0 \\ \text { Covering with yellow cloth/muslin/blanket } & 203 & 47.7 \\ \text { Breastfeeding often } & 70 & 16.4 \\ \text { †Other } & 28 & 5.9\end{array}$

Bathing the infant in water with gold, making the infant sleep under white lamp

To recover from jaundice

$\begin{array}{lrr}\text { No practices } & 146 & 34.3 \\ \text { Taking to doctor } & 175 \\ \text { \& Other } & 41.1 \\ \text { Por } & 24.6\end{array}$

Covering with yellow muslin/blanket, breastfeeding often, taking to hodja

For moni

For moniliasis

$\begin{array}{lrr}\text { No practices } & 184 & 43.1 \\ \text { Taking to doctor/drug } & 32.3 \\ \text { ๆOther } & 138 & 104\end{array}$

'Other

'Cleaning with carbonated water, throwing cotton cleaned with carbonated water on the ceiling and believing that the infant gets well when it falls

down, making the infant drink water, cleaning with starch, cleaning the mouth with water from the container dogs drink water, putting on ring

For diaper rash

$\begin{array}{lrr}\text { No practices } & 145 & 34.1\end{array}$

\begin{tabular}{lr} 
Taking to doctor/applying cream & 141 \\
\hline
\end{tabular}

\begin{tabular}{lr} 
Using powder & 62 \\
\hline
\end{tabular}

$\begin{array}{ll}\text { †O Other } & 78 \\ \end{array}$

${ }^{\dagger \dagger}$ Putting on olive oil, changing diapers frequently, bathing the infant frequently, washing the infant's bottom with salted water

For cough

$\begin{array}{lrr}\text { No practices } & 149 & 34.9\end{array}$

$\begin{array}{lr}\text { Taking to doctor/using drug } & 163 \\ & 38.4\end{array}$

\begin{tabular}{lr} 
Using herbal products ${ }^{* *}$ & 114 \\
\hline
\end{tabular}

+Using herbal products(linden, ginger, cinnamon, rose hip, cumin), making the infant drink olive oil, making the infant drink honey lemon tea

For diarrhea

$\begin{array}{lrr}\text { Taking to doctor/using drug } & 145 & 33.8 \\ & 41.3\end{array}$

- $105 \quad 24.9$

$\S \S$ Making the infant drink water frequently, breastfeeding often, making the infant eat banana

For constipation

\begin{tabular}{|c|c|c|}
\hline No practices & 147 & 34.5 \\
\hline Taking to doctor/using drug & 118 & 27.6 \\
\hline "Other & 161 & 37.9 \\
\hline
\end{tabular}

โा Massaging the abdomen, making the infant drink olive oil, making the infant drink water frequently, making the infant eat fruit puree, soap from

the anus as suppository, making the infant drink compost, making the infant drink fish oil

For fever

$\begin{array}{llr}\text { No practices } & 31.5 \\ \text { Cold compress } & 134.1\end{array}$

\begin{tabular}{lr} 
Cold compress & 134 \\
\hline & 37.1
\end{tabular}

\begin{tabular}{lr} 
Taking to doctor/using drug & 85 \\
\hline
\end{tabular}

$\begin{array}{lr} & 40 \\ +\dagger & 49\end{array}$

${ }^{+1+T}$ Taking off clothes, putting on water with vinegar, putting on water with raki

For gas

No practices

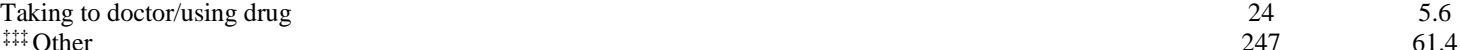

+ Massaging, rubbing the back, making the infant drink herbal tea/tea, putting on apple oil

For infants who cry and who are uneasy all the time

No practices

Taking to doctor

qOther

$138 \quad 31.8$

$47 \quad 11.0$

$241 \quad 57.2$

${ }^{\top}$ Reciting prayer, holding the infant in the lap, making the infant let out gas after breastfeeding, breastfeeding, rocking the baby, giving pacifier, collecting rope from seven neighbors

Before the first feeding religious ritual

$\begin{array}{lr}\text { No practices } & 366 \\ \text { tother } & 60 \\ \text { Waiting for reciting of azan, Making the infant drink zam-zam before first feeding, Putting date on the infant's mouth before first feeding , Mak }\end{array}$

iो Waiting for reciting of azan, ,Making the infant drink zam-zam before first feeding, Putting date on the infant's mouth before first feeding, Making the infant drink blessed water before first feeding

Total

*Since the answers were more than one, the percentages were taken over " $n$ ".

426

100.0 
Table 3. Distribution of cultural beliefs conducted of infants by the participants ( $n=426)$

\begin{tabular}{|c|c|c|}
\hline *Variable & $\mathbf{n}$ & $\%$ \\
\hline \multicolumn{3}{|l|}{ To protect the infant from evil eye } \\
\hline No practices & 129 & 30.3 \\
\hline Putting on evil eye bead & 158 & 37.1 \\
\hline Other & 139 & 32.6 \\
\hline \multicolumn{3}{|c|}{ 'Reading prayer, putting on amulet, pouring lead for evil eye, putting sour apple in swaddle } \\
\hline \multicolumn{3}{|c|}{ For the infant to be beautiful } \\
\hline No practices & 234 & 54.9 \\
\hline Putting mother's milk on the infant's face & 131 & 30.8 \\
\hline Tinging the eyes & 61 & 14.3 \\
\hline \multicolumn{3}{|l|}{ For the infant's body to be smooth, } \\
\hline No practices & 237 & 55.6 \\
\hline Swaddling & 189 & 44.4 \\
\hline \multicolumn{3}{|l|}{ For the infant not to smell bad } \\
\hline No practices & 168 & 39.4 \\
\hline Adding salt in the bathing water & 115 & 27.0 \\
\hline Bathing the infant frequently & 65 & 15.3 \\
\hline$\$$ Other & 78 & 18.3 \\
\hline \multicolumn{3}{|c|}{ Salting the infant, putting on rose water, baby lotion, reciting Quran } \\
\hline \multicolumn{3}{|c|}{ To prevent the infant from getting sick in the first forty days } \\
\hline No practices & 171 & 40.0 \\
\hline Putting Quran on the cradle & 143 & 33.6 \\
\hline${ }^{\S}$ Other & 112 & 26.4 \\
\hline
\end{tabular}

${ }^{\S}$ Putting Quran on the cradle, putting knife under the cradle, reciting Quran, not showing to women who are in their periods, tying red, hanging the father's clothes in the infant's room

\begin{tabular}{lcc}
\hline For the infant to be talkative & 276 & 64.8 \\
No practices & 136 & 31.9 \\
Talking to the infant & 14 & 3.3 \\
Making the infant kiss bird beak & 335 & \\
\hline For infants to be a sweet talker & 91 & 21.4 \\
\hline No practices & & \\
Putting honey on the infant's mouth before first feeding & 163 & 37.2 \\
\hline For the infant to be a person in the future & 263 & 62.8
\end{tabular}

*Burying in the garden of an educational institution, burying in the mosque, burying in the house or garden, throwing the stump on the ceiling, keeping in the bag, tying to the cradle

* Since the answers were more than one, the percentages were taken over "n".

The practices for the umbilical stump that fell off were "burying in the garden of an educational institution, burying in the mosque, burying in the house or garden, throwing the stump on the ceiling, keeping in the bag, tying to the cradle" $(62.8 \%)$ for the infant to be a person in the future

\section{Discussion}

The findings of the study to determine the traditional methods puerperal women apply for babycare in the Eastern region of Turkey were discussed in this section. It is stated that traditional practices of baby care are observed especially in families who live in rural areas far away from health centers and who have a low level of education, many family members, poor socioeconomic status, no social security, and no job and in immigrant families (Cetinkaya et al., 2008; Bozkus et al., 2011). In this study, some traditional practices were determined because it was conducted in a region regarded as rural.

In the study, it was found that the first place referred to is health institutions with a rate of $73.7 \%$ when the infant gets sick. In studies conducted, it has been stated that the rate of taking the infant to doctor immediately when the infant gets sick is about 53\%. The number of people who referred to primary, 
secondary and tertiary health institutions within the last 14 years went up to 8.6 from 3.2 and the rate of referring to especially secondary and tertiary health institutions reached $70 \%$. The rate of infant death which is 31.7 globally is 9.7 in Turkey and this can be considered as a result of the fact that health institutions are mostly preferred when infants get sick (Health Statistics Yearbook, 2016).

In the study, it was found that the participants conducted practices such as not making the infant bathe, cleaning with alcohol, putting powder on, putting on batticon, bathing the infant in salty water and putting ash on the stump to help the stump fall off. In a comparative study between Turkey and Iran in literature, it was reported that alcohol and iodize tincture were mostly applied for the umbilical stump to fall off (Ozsay and Katabi, 2008), olive oil and powder were used in Turkey (Turkey Demographic and Health Survey, 2013), butter was used in Ethiopia(Amare, 2014), while cow's manure was used in Uganda (Beinempaka et al., 2014) In the present study, it was found that women used alcohol, powder and batticon for the stump to fall off, even though low in number, in addition to traditional practices such as bathing the infant in salty water and putting ash on the stump. World Health Organization recommends waiting for the umbilical stump to fall off and to use antiseptic solution only in developing countries such as Africa and Afghanistan (Toruner and Buyukgonenc, 2012).

It was found that women who participated in the study mostly conducted unharmful practices such as covering with yellow cloth/muslin/blanket for the infant not to get jaundice or to recover. In addition, bathing the infant with water containing gold, making the infant sleep under white lamp and taking the infant to a hodja were also conducted in low rates. Studies conducted show that practices such as making the infant wear yellow things, putting gold on the infant (Is1k et al., 2010; Calıskan and Bayat, 2011; Yigitalp and Gumus, 2017), putting on yellow cloth (Isik et al., 2010) and making the infant drink mineral water (Bilgen Sivri, 2012) are conducted for the infant not to get jaundice or to recover. Jaundice is a condition that is accepted as pathological within the first 24 hours of infants and it should be monitored (Toruner ve Buyukgonenc, 2012). Mothers are advised to breastfeed infants frequently to prevent jaundice. In addition, it is not harmful to conduct unharmful practices such as those found in this study (covering with yellow things, putting on gold).

It was found that the participants in the study generally used sodium bicarbonate for moniliasis; however, although low in number, there were also participants who conducted harmful practices such as using starch or cleaning the infant's mouth with water from a container from which dogs drank things. Studies in literature show that in case of moniliasis, practices were conducted such as putting mineral water on the infant's mouth (Bolukbas et al., 2009; Caliskan and Bayat, 2011; Demirbag et al., 2012; Bilgen Sivri, 2012; Yigitalp and Gumus, 2017;), cleaning with sodium bicarbonate, sugar, mother's hair and dry cloth (Caliskan and Bayat, 2011; Bilgen Sivri, 2012; Demirbag et al., 2012). In study, the result that most of the mothers used sodium bicarbonate for moniliasis is in accordance with modern medicine. However, it is thought that traditional practices such as cleaning the infant's mouth with water from a container from which dogs drank things, cleaning with hair, and putting on starch can cause moniliasis to increase, recovery to be delayed and even the infant to get other infections (Demirbag et al., 2012).

In the present study, it was found that the participants used olive oil and powder to prevent diaper rash and washed the infant's bottom with salty water. Studies conducted show that powder, olive oil (Arisoy et al., 2014), salt (Yigitalp and Gumus, 2017) and drugs are used to prevent diaper rash (Caliskan ve Bayat, 2011). Using olive oil for diaper rash is a recommended practice since it prevents the scratchiness which occurs on the skin due to ammoniac. However, using powder is not recommended since it can cause scratchiness by accumulating on the inguinal area and since it can cause aspiration in respiratory tract (Toruner and Buyukgonenc, 2012).

In the study, it was found that the participants used herbal products, olive oil and honey lemon tea for cough. Other studies conducted showed that various mixtures (honey, grape molasses, aspirin, olive oil, cologne, paraffin oil, ethyl alcohol) were put on the infant's back or chest to heal the infant's cough and also hot towel, angora wool gloves and newspaper were put on the infant's chest. In another study, it was reported that the infant was made to drink grape molasses, honey, mint-lemon, olive oil, ginger-honey (Bilgen Sivri, 2012). Other practices were making the infant drink black pepper added boiled milk or tea, making the infant eat paraffin oil after dropping sugar, jumping on trash by putting key on the infant's throat, putting hot milk, cologne, vicks on the infant's back, making the infant drink grape molasses with milk or butter, or boiled parsley (Toruner and Buyukgonenc, 2012). The results of this study are similar to the results in literature. 
In study, it was found that the participants took their infants to doctor in case of diarrhea and they conducted correct practices such as making the infant drink water, breastfeeding often and making the infant eat banana. Infants are often taken to doctor in case of diarrhea (Memona et al., 2013; Ugurlu et al., 2013). When studies on the subject are examined, it has been found that instead of traditional practices, most of the mothers take their infants to doctor in case of diarrhea. This is a significant result for infant health (Ugurlu et al., 2013). In addition, women were found to conduct practices such as giving ORS and solid food (Memona et al., 2013; Ugurlu et al., 2013), making the infant drink dark tea, mint-lemon and decreasing greasy food (Wang et al., 2008). It can be said that taking infants to doctor most of the time in case of diarrhea is a positive behavior in case of health.

In the present study, it was found that the participants massaged the abdomen, made the infant drink olive oil, eat fruit puree, gave soap from anus for suppository, made the infant drink stewed fruits or fish oil for constipation. Studies conducted showed that mothers conducted practices such as making the infant drink olive oil (Bilgen Sivri, 2012), placing olive oil or soap in the anus and used drugs for constipation (Yalcin, 2012; Arisoy et al., 2014). Placing soap in the anus can harm the anus mucosa; however, making the infant drink olive oil can be accepted to be an effective practice.

In the present study, it was found that the participants conducted practices such as cold compress, taking to doctor/using drug, taking off clothes, putting on water with vinegar and raki in case of fever. In literature, the first practice to be referred to has been giving an antipyretic, applying cold water and water with vinegar (Arisoy et al., 2014) and warm water application. The results of this study are similar to the results in literature.

In the present study, it was found that the participants conducted practices such as massage, rubbing the back, taking to doctor/using drug, making the infant drink herbal tea/tea and putting on apple oil for gas. Studies in literature on gas pains revealed practices such as burning a cloth and putting the cinder on abdomen (Isik et al., 2010), giving antiflatulent, making the infant drink fennel tea, aniseed tea and chamomile tea (Caliskan and Bayat,2011). Similar results were obtained in the present study.

In this study, it was found that the participants conducted practices such as reciting prayer, holding the infant in the lap, making the infant let out gas after breastfeeding, breastfeeding, rocking the baby, giving a pacifier, collecting rope from seven neighbors for infants who cry and who are uneasy all the time. In literature, it has been reported that methods such as carrying the infant, bathing the infant frequently, warm towel compression, praying, putting evil eye bead and putting on amulet were used by families to calm infants who cried and got uneasy all the time (Cetinkaya et al., 2008; Isik et al., 2010; Yalcin, 2012; Bilgen Sivri, 2012). The results of this study are similar to the results in literature.

In this study, it was found that the practices of putting honey in the newborn's mouth, making the infant drink zam-zam, putting date on the infant's mouth and waiting for reciting the Quran before the first feeding of the infant are still practiced even if these practices are applied by a minority. Breastfeeding the infant within the first 30 minutes after birth is important both the breastfeeding reflex of the infant and for stimulating the infant's lactation (Toruner and Buyukgonenc, 2012). Studies conducted in Turkey show that in the past infants were breastfed every half an hour or every hour (Isik et al., 2010; Caliskan and Bayat, 2011; Arisoy et al., 2014), while there were also mothers who waited for three azans to feed the infant. Studies show that infants are first fed with sugared water (Yigitalp and Gumus, 2017). Similarly, it was found that $71 \%$ of the mothers in Pakistan breastfed their infants within the first hour and before they gave the colostrum, they gave salty water $(44 \%)$, cow's milk (26\%), and zamzam (14\%) to their infants (Memona et al., 2013). In literature, it has been stated that it is very important for the infant to get colostrum in the first 5 days due to its effect of regulating gastrointestinal system functions and protecting the infant from infections in addition to having high bioefficacy for the infant to grow up and develop (Samur, 2008). According to TNSA 2013 data, it has been reported that within the first hour of birth, one out of two children is breastfed, the rate of early breastfeeding is higher in mothers with a high level of welfare, infants are fed with other nutrients at a rate of $26 \%$ before mother's milk and that this situation does not differ in terms of level of education and welfare (Turkey Demographic and Health Survey, 2013). In the present study, the results that practices are applied such as putting honey and date on the newborn's mouth before first feeding, making the infant drink zam-zam or blessed water and waiting for the azan to be recited before first feeding, although practiced in low numbers, show that some social practices are transferred from generation to generation.

In the present study, it was found that the participants conducted practices such as reading 
prayer, putting on amulet, pouring lead for evil eye, putting sour apple in swaddle to protect the infant from evil eye. Such practices may not be harmful in terms of infants' health. However, infants' health may be negatively influenced when the search for healthy behavior is influenced by thinking that the infants' illness can be resulting from evil eye.

In the study, it was found that the baby was put on their face for the baby to be beautiful and riding in the eyes. Similarly, in the studies conducted in different regions, it is stated that the baby's face is taken from breast milk, lemon and almond oil is applied to eyebrows and eyes (Isik et al., 2010; Bilgen Sivri, 2012; Arisoy et al., 2014) in order to make the baby beautiful. In the study, breastfeeding is harmless for babies to be beautiful but harmful for conjunctivitis.

It was found that about half of the participants continued swaddling. In literature, it is stated that one of the traditional practices which can negatively influence infant health is swaddling, which is considered to be among developmental hip dysplasia risk factors (Toruner and Buyukgonenc, 2012; Sevig and Tanriverdi, 2014). It has also been stated in studies conducted in Turkey that the tradition of swaddling is quite common and swaddling is conducted for the infant to have shapely arms, legs and body (Cetinkaya et al., 2008; Isik et al., 2010; Yigit and Gumus, 2017), to sleep comfortably, for the infant not to have the waist hurt and not to feel cold (Gokduman and Akdolun Balkaya, 2013). However, the fact that infants cannot feel comfortably when their arms and legs are covered is considered to be among risk factors for developmental hip dysplasia and this is considered to be risky in terms of health.

In order to prevent the baby from smelling, it was determined that practices such as salting the baby, riding the rose water, using baby lotion and reading the Quran were carried out in this study. It has also been stated in the studies conducted in Turkey that the tradition of salting is quite common (Cetinkaya et al., 2008). The application of salting to newborns is harmful to health because it can cause dehydration and loss of fluid from the body. The study is carried out in harmless applications (rose water and baby lotion riding and reading) in order not to smell the baby.

In the present study, it was found that the participants conducted practices such as putting Quran on the cradle, putting knife under the cradle, reciting Quran, not showing the baby to women who are in their periods, tying red, hanging the father's clothes in the infant's room to prevent the baby from getting ill in the first 40 days. It is the belief in the existence of the soul that the gin, fairy and devil affects the woman and the newborn. There are examples of similar applications in Turkey (Bozkus Egri and Konak, 2011). Preventing the baby from getting ill in the first 40 days is a cultural belief.

In the study, it was found that after the infant's umbilical stump falls off, the participants conducted practices such as burying in the garden of an educational institution or mosque, burying in the house or garden, throwing on the ceiling, keeping it in a bag and tying on the cradle. In Turkish tradition, the stump is not thrown away after it falls off and it is kept according to what kind of a person the family wants the infant to become (Ozsoy and Katabi, 2008; Bilgen Sivri, 2012). It is stated that the stump is buried to the mosque courtyard if the family wants the infant to be a religious person, in the courtyard of the faculty of medicine if the family wants the infant to become a doctor and in the garden of the house if the family wants the infant to be domestic (Bilgen Sivri, 2012). As a similar practice, the infant's umbilical stump is buried under a specially chosen tree in Nigeria so that the child can have a long life (Okpomeshine, 2011). In our study, it was found that the practices related with umbilical stump that falls off have been found to be practices which are not harmful for the infant's health.

\section{Limitations of the Study}

The fact that the study was conducted on puerperas who gave birth in the puerperal service of the Training and Research Hospital in a city in the east of Turkey is a limitation in terms of the generalizability of the results. Conducting similar studies in each region of the country is important in terms of finding out traditional practices.

\section{Conclusion}

In this study, it was found that the puerperal women conducted traditional practices such as for umbilical stump to fall off, to prevent jaundice, to recover from jaundice, for moniliasis, for diaper rash, for cough, for diarrhea, for constipation, for fever, for gas for infants who cry and who are uneasy all the time, before the first feeding religious ritual in the infants care. In addition, it was determined that puerperal women have some cultural beliefs for the evil eye, the baby to be beautiful, the body to be smooth, not to smell, to be talkative, to be sweet, forty not to stop in the future. Some of the traditional methods used by puerperal women are detrimental to health. Nurses, who have an active role in protecting and developing individuals' health are expected to conduct such studies so that they can provide more effective and qualified care. The fact that nurses are aware of the 
traditional practices for the cultural structure and infant care of societies they are serving will be guidance in shaping training programs for the society and mothers. In addition, detailed anamnesis taken by nurses in postnatal periods, planned trainings about traditional methods are significant in terms of preventing the possible results of traditional practices.

Ethics Committee Approval: Before starting the study, written permission from the institution the research was conducted in and approval from Recep Tayyip Erdoğan University Non-Invasive Clinical Researches Ethical Board (decision number: 08/06.01.2017) were taken.

Peer-review: Externally peer-reviewed.

Author Contributions: Concept. A.Y.Y., Y.A.D.; Design- A.Y.Y., Y.A.D., H.G.U.; Materials-. A.Y.Y., Y.A.D., H.G.U.; Data Collection and Processing. Y.A.D. Literature Review-. A.Y.Y., Y.A.D., H.G.U.; Writing- A.Y.Y., Y.A.D., H.G.U.; Critical Review. A.Y.Y., Y.A.D., H.G.U.

Conflict of Interest: No conflict of interest was declared by the authors.

Financial Disclosure: The authors declared that this study hasn't received no financial support.

\section{References}

Amare Y. Umbilical cord care in Ethiopia and implications for behavioral change: A qualitative study. BMC Int Health Hum Rights 2014; 14: 12. doi: 10.1186/1472-698X-14-12.

Amin R, Shah MN, Becker S. Socioeconomic factors differentiating maternal and child health-seeking behavior in rural Bangladesh: A cross-sectional analysis. International Journal for Equity in Health 2010; 9 (9): 1-11. doi:10.1186/1475-9276-9-9

Arisoy A, Canbulat N, Ayhan F. Traditional methods applied in caring for infants of mothers in Karaman. Journal of Anatolian Nursing and Health Sciences. 2014; 17: 23-31.

Beinempaka F, Tibanyendera B, Atwine F, Kyomuhangi T, Macdonald NE. The practice of traditional rituals and customs in newborns by mothers in selected villages in southwest Uganda. Paediatr Child Health 2014; 19: 72.

Bilgen Sivri B. Traditional practices about child and mother care of the mothers who owner 0-12 month baby. Erciyes Üniversity. Master Thesis. 2012.

Birdee SG, Phillips SR, Davis BR, Gardiner P. Factors associated with pediatric use of Complementary and Alternative Medicine. Pediatrics 2009; 125 (2): 248-257.
Boer H, Lamxay V. Plants used during pregnancy, childbirth, and postpartum healthcare in Lao PDR: A comparative study of the Brou, Saek and Kry ethnic groups. Journal of Ethnobiology and Ethnomedicine 2009; 5 (25). doi:10.1186/17464269-5-25.

Bozkaya GO, Akgün I, Birgi E, Cinkoglu A, Gog K, Karadeniz D. Practice of alternative medicine in childhood by parents. Journal of Dokuz Eylul University Medical Faculty. 2008; 22 (3): 129135.

Bozkus Egri G, Konak A. Traditional belief related to postpartum period and samples for practises from Turkey and the World. ZfWT 2011; 3(1): 143155.

Bolukbas N, Erbil N, Altunbas H, Arslan Z. Traditional practices about childcare of the mothers who owner 0-12 month baby. Journal of Human Sciences. 2009; 1: 165-8.

Bulbul HS, Turgut M, Koyluoglu S. Parents' views about alternative practices in children. Journal of Child Health and Diseases. 2009; 52: 195-202.

Celasin SN, Ergin D, Atman U. Attitudes and knowledge concerning high temperature of mothers have 0-6 age group infants who are hospitalized due to high temperature ailments. Firat University Journal of Health Sciences. 2008; 22 (6): 315-322.

Calıskan Z, Bayat M. Infant care practices and influencing factors: An example of Cappadocia. Journal of Anatolian Nursing and Health Sciences. 2011; 14: 23-30.

Cetinkaya A, Ozmen D, Cambaz S. Traditional practices associated with infant health among the 15-49 aged women who have children in Manisa. Journal of Cumhuriyet University School of Nursing. 2008; 12: 39- 46.

Demirbag CB, Tanir KM, Kuguoglu S. Oral thrush infection in infants between 1-12 months and approaches the traditional used by mothers for treatment. Electronic Journal of Vocational Colleges 2012; 136-44.

Gokduman M, Akdolun Balkaya N. The traditional practices of increasing the quantity of mothers of 0-6 month. Journal of Adnan Menderes University Health Sciences Faculty. 2013; 14: 31-1.

Gokduman M, Balkaya AN. The use of herbal tea to increase breast milk and influencing factors. Dokuz Eylul University E-Journal of Nursing Faculty. 2010; 3(4): 187-194.

Health Statistics Yearbook, 2016. Ankara. 
Isik T, Akcinar M, Kadioglu S. Traditional practices applied to mother and newborn during pregnancy, labor and postpartum periods in Mersin. International Journal of Human Sciences. 2010; 7: 63-4.

Kesterton JA, Cleland J. Neonatal care in rural Karnataka: Healthy and harmful practices, the potential for change. BMC Pregnancy and Childbirth 2009; 9 (20): 1-13.

Memona ZA, Khanb MI, Soofic S, Muhammad S, Bhuttac ZA. A cross sectional survey of newborn care practices in rural Sindh, Pakistan: Implications for research and policy. J Neonatal Perinatal Med 2013; 6: 137-44.

Mollahaliloglu S, Kosdak M, Eryilmaz Z. The Ministry of Health of Turkey Health Statistics Yearbook, 2008. Ankara. 2011.

Okpomeshine C. Traditional birthing practices in Igbo Land, Nigeria. Int J Interdisciplinary Social Sciences 2011; 6: 93-8.

OpenEpi Version 3.01. (http://www.openepi.com)

Ozsoy SA, Katabi VA. Comparison of traditional practices used in pregnancy, labour and the postpartum period among women in Turkey and Iran. Midwifery 2008; 24: 291-300.

Samur G. Mother's milk. Ministry of Health Publication Number: 726, Klasmat Press (in Turkish). 2008.

Sevig U, Tanriverdi G. Interculturel Nursing. 1st press. Akademi Press and Publishing (in Turkish). İstanbul. 2014.

Titaley RC, Hunter LC, Heywood P, Dibley JM. Why don't some women attend antenatal and postnatal care services? a qualitative study of community members'perspectives in Garut, Sukabumi and Ciamis districts Of West Java Province, Indonesia. BMC Pregnancy and Childbirth 2010; 10 (61): 212.

Toruner KE, Buyukgonenc L. The Basic Nursing Approaches in Child Health. Göktuğ Publishing, Amasya. 2012.

Turkey Demographic and Health Survey Hacettepe University Institute of Population Studies 2013. Ankara.

Ugurlu SE, Basbakkal Z, Dayilar H, Coban V, Ada $V$. Examination of the traditional practicies about child care of the mothers in Odemiş. Gümüşhane University Journal of Health Sciences 2013; 2 (3).

Vurur S, Vurur G, Kocak B, Satılmisoglu O. Determination of traditional practices for breastfeeding. Intercultural Approach Symposium in Nursing and Midwifery 2009; 100.
Wang X, Wang Y, Zanzhou S, Wang J, Wang J. A population based survey of women's traditional postpartum behaviors in Northern China. Midwifery 2008; 19: 238-45.

Yalcin H. Traditional practice related to pregnancy, the natal and postnatal period and baby care (Karaman sample). Journal of Child Health and Diseases. 2010; 55 19-31.

Yigitalp G, Gumus F. Traditional infant care practices of women aged 15-49 in Diyarbakır. Turkish Journal of Pediatric Disease 2017; 3: 188-196. 